\title{
Acta Endoscopica vers le futur...
}

\section{Acta Endoscopica on the way to future}

\author{
G. Lesur \\ (C) Lavoisier SAS 2014
}

Pendant l'été, on le sait un peu pluvieux, le monde de l'édition a continué de travailler. Ainsi nous avons appris le 3 septembre dernier que le programme en langue française de Springer, notre éditeur jusqu'à maintenant, avait été vendu au groupe français Lavoisier SAS, éditeur scientifique, technique et médical, publiant essentiellement en langue française. Il a été néanmoins décidé que les revues, dont bien entendu Acta Endoscopica, continueraient d'être distribuées sur SpringerLink au moins jusqu'en décembre 2016. Même si ce changement n'aura dans l'immédiat a priori aucune conséquence pour vous, lecteurs fidèles sur papier et/ou sur le net d'Acta Endoscopica, il est important que vous en soyez informés. Il est difficile aujourd'hui d'imaginer les possibles conséquences à court, comme à moyen et long termes de ce changement. Nous avons désormais quelques mois pour réfléchir tous ensemble à ce que nous souhaitons faire de cette revue qui est la vôtre. Et vos souhaits, remarques, critiques et, pourquoi pas, encouragements, sont attendus dès maintenant !

Vous le savez, la SFED a décidé il y a quelques années de faire d'Acta Endoscopica sa revue officielle. Ce choix de publier en français, préférentiellement à propos d'endoscopie digestive, de conserver le support papier, d'augmenter le volume de sa production comme de diversifier son contenu, notamment en développant son versant formation médicale continue avec le soutien actif de la FMC/HGE, s'est avéré le bon et Springer nous a aidés dans ce développement. Nos chemins vont donc maintenant se séparer sans doute et avant tout pour une raison que nous connaissons tous, la perte d'influence de la langue française, et donc de la culture française dans le monde.
Si l'on ne peut que déplorer cette évolution il faut bien se rendre à l'évidence, cette perte d'influence est très importante et irréversible. Sans entrer dans le complexe et passionné débat du pourquoi, force est de constater que la France traverse depuis un moment une mauvaise passe et que nos dirigeants qui se gaussent régulièrement de « Francophonie » n'ont pas compris que la francophonie n'était pas exclusivement cette belle langue que beaucoup aiment et nous envient mais également des échanges, du commerce, l'accueil d'étudiants étrangers, des rencontres culturelles régulières, etc. Car faire vivre la langue française et la culture française, non par des mots mais avec des actes, aurait pu générer des emplois, des ressources, du développement, des échanges et leurs naturelles retombées économiques ! Plutôt que d'encourager ces échanges, on a un temps rendu kafkaïen l'accueil des étudiants étrangers, on a fermé ou asphyxié les instituts français dans les grands capitales et j'en passe...Et ceux et celles d'entre nous qui se rendent en terre francophone constatent chaque jour un peu plus la perte de place de notre langue et de notre culture. Et quelle tristesse de voir qu'il en est de même dans des pays aussi viscéralement attachés à la langue française que le Liban, un exemple malheureusement parmi d'autres.

Et s'il existe d'autres raisons à ce choix de Springer, moins évidentes, voire moins avouables que celle-ci, l'avenir nous le dira... Quoiqu'il en soit et en attendant, tout le conseil d'administration de la SFED (dont sept membres seront à élire ou réélire bientôt, avis aux amateurs...) vous souhaite un bon Vidéo-Digest 2014 et une bonne lecture de cet avant-dernier numéro de l'année 2014 d'Acta Endoscopica.
G. Lesur $(\bowtie)$

Rédacteur en chef, hôpital Ambroise Paré, F-92100 Boulogne-

Billancourt

e-mail : gilles.lesur@apr.aphp.fr 